\title{
Urology residency training: Time to enter the 21st century
}

\author{
Naji J. Touma, MD, FRCSC \\ Department of Urology, Queen's University, Kingston, ON
}

See related article on page 168 .

Cite as: Can Urol Assoc J 2012;6(3):175-6. http://dx.doi.org/10.5489/cuaj.12120

$\mathrm{P}$ rior to the last century, surgeons perfected their craft through preceptorships. Early in the last century, Halsted introduced the German residency system of graded responsibility to North America. ${ }^{1}$ This system remains the cornerstone of surgical education. However, there has been tremendous change in surgical techniques, especially related to the practice of urology. We have witnessed the introduction of flexible ureteroscopy with laser lithotripsy and percutaneous nephrolithomy for the treatment of renal calculi. In addition, with the advent of laparoscopy and robotics, the surgical treatment of many urological diseases has changed dramatically. Despite this rapid evolution in urological practice, changes in surgical education and evaluation have lagged behind. The authors highlight the disparity in the use of novel teaching adjuncts among various programs. ${ }^{2}$ In addition, the incorporation of such adjuncts into formal assessments seems to be applied in a heterogeneous manner.

Although many believe surgical expertise is a reflection of an individual's intrinsic ability, empiric research has confirmed the importance of practice. ${ }^{3,4}$ Simulators are instruments that reproduce, under artificial conditions, components of surgical tasks. ${ }^{5}$ Types of models include cadaver, animal, bench and computer software-based simulators. Cadaver models provide true anatomic representation, but the tissue quality might not be as realistic as living tissue. Live animals provide a model with appropriate tissue texture; however, anatomy may not be entirely representative of its human counterparts. Additionally, the use of human cadavers and live animals tends to be expensive and raises ethical issues. Bench models sacrifice fidelity for safety, availability, portability and lower overall cost. ${ }^{1,6}$ With advances in material technology and computer hardware and software, simulators have become more advanced, with higher fidelity and more capacity for assessment and feedback. Fidelity of a model refers to its realistic features. A simulator does not need to look realistic as long as the pertinent steps of the procedure are performed. That is, a low-fidelity simulator can provide the same benefit as a high-fidelity model. ${ }^{7}$ The most important outcome of simulators is the ability for skills learned on a model to be translated into improved performance in the clinical setting. This concept is referred to as transferability. ${ }^{3}$ Many bench and virtual reality simulators have been developed to reproduce many urological procedures. ${ }^{8}$ Some of these simulators are currently commercially available. While simulators can act as adjuncts for the acquisition of technical skills, they are no substitution to practice in real-life surgical conditions.

The second aspect highlighted in this study is the lack of uniformity in assessing surgical skills across programs. ${ }^{2}$ The ideal components of a sound assessment test are reliability and validity. Reliability refers to the reproducibility of the results produced by the assessment; validity refers to whether a test measures what it purports to measure.

Competency-based medical education (CBME) is an emerging concept in training that is being advocated as a substitute or, at least, a complement to the traditional time-based residencies. A white paper has been submitted to the Royal College of Physicians and Surgeons of Canada advocating a shift towards a CBME approach. ${ }^{9}$ In the United States, the Accreditation Council for Graduate Medical Education began an initiative in 1998 known as the outcome project; the program focuses on the competency domains. ${ }^{10}$ The Division of Orthopaedics at the University of Toronto and the Royal Australasian College of Psychiatry pilot projects are current examples of CBME. ${ }^{9}$

A successful shift towards a CBME approach requires three critical components: (1) identifying the required abilities; (2) identifying ways to teach the required abilities; and 


\section{Touma}

(3) identifying ways to assess these abilities. It is obvious that, as a specialty, we have a lot of work on these three fronts to move into a 21 st century model of training.

Competing interests: None declared.

This paper has been peer-reviewed.

\section{References}

1. Wanzel KR, Ward M, Reznick RK. Teaching the surgical craft: From selection to certification. Curr Probl Surg 2002;39:573-659. htrp://dx.doi.org/10.1067/mog.2002.123481

2. Nayan M, Houle A.M., McDougall E, et al. Establishing milestones in urology training: A survey of the Canadian Academy of Urological Surgeons. Can Urol Assoc J 2012;6:168-74. http://dx.doi. org/10.5489/cuaj. 11248

3. Hamstra SJ, Dubrowski A, Backstein D. Teaching technical skills to surgical residents. Clin Orthop Relat Res 2006;449:108-15.
4. Ericsson KA. Deliberate practice and the acquisition and maintenance of expert performance in medicine and related domains. Acad Med 2004;79:S70-81. http://dx.doi.org/10.1097/00001888-20041000100022

5. Krummel TM. Surgical simulation and virtual reality: The coming revolution. Ann Surg 1998;228:635-7. http://dx.doi.org/10.1097/00000658-199811000-00002

6. Grober ED, Hamstra SJ, Wanzel KR, et al. The educational impact of bench model fidelity on the acquisition of technical skill. Ann Surg 2004;240:374-81. http://dx.doi.org/10.1097/01. sla.0000133346.07434.30

7. Matsumoto ED. Low-fidelity ureterscopy models. J Endourol 2007;21:248-51. http://dx.doi. org/10.1089/end.2007.9984

8. Matsumoto ED, Touma NJ. Textbook of Simulation: Skills and Team Training. 2012; Chap. 61:864.

9. Snell L, Gillis K, Fletcher B, et al. Competency Based Medical Education. hittp://rcpsc.medical.org/ residency/fmec/CBME.pdf. (Accessed May 9, 2012).

10. Accreditation Council for Graduate Medical Education [ACGME]. 2001 - present. Outcome project. Chicago (IL): ACGME. http://www.acgme.org/ (Accessed May 9, 2012).

Correspondence: Dr. Naii J. Touma, Kingston General Hospital, 76 Stuart St., Kingston, ON K7L 2V1; nitouma@gmail.com 